\title{
EBSD Characterization of Microstructural Variations in Solid-State Welds as a Function of Distance from the Weld Interface in Ti-17
}

\author{
Jonathan Orsborn $^{1,2}$, Thomas F. Broderick ${ }^{3}$, Hamish Fraser ${ }^{1}$ \\ 1. Center for the Accelerated Maturation of Materials, Department of Materials Science and Engineering, \\ The Ohio State University, Columbus, $\mathrm{OH}$ \\ 2. Center for Electron Microscopy and Analysis, The Ohio State University, Columbus, OH \\ ${ }^{3 .}$ GE Aviation, Materials and Process Engineering, One Neumann Way, Cincinnati, OH
}

Recent advances in welding technology have enabled the aerospace industry to reduce further the weight of aircraft, by welding titanium alloys reliably. Solid-state welding, in which two metal pieces are welded without either one melting, has recently been proven to produce reliable and consistent welds, and is rapidly becoming the preferred method for joining titanium. Rapid heating rates, short hold-times, plastic deformation, thermal gradients, and fast cooling rates all contribute to the non-equilibrium nature of the process. All of these factors vary with respect to their proximity to the weld interface, resulting in various regions of the welded piece. Thus, the resulting microstructure varies with distance from the weld plane, and can typically be divided into four zones: the dynamically recrystallized zone (DRX), the thermo-mechanically affected zone (TMAZ), the heat-affected zone (HAZ) and the base material (BM) [1]. Commercial titanium alloys have two equilibrium phases: the low-temperature hexagonal closepacked (hcp) phase, $\alpha$, and the high-temperature body-centered cubic (bcc) phase, $\beta$. Ti-17 (Ti-5Al-4Cr$4 \mathrm{Mo}-2 \mathrm{Sn}-2 \mathrm{Zr}$ ) is a metastable- $\beta$ alloy, meaning that it can retain essentially $100 \% \beta$ phase, upon fast cooling [2]. Since the mechanical properties of titanium alloys are particularly dependent upon microstructure, it is important to understand the phase transformations occurring and the microstructures produced during the solid-state welding process. Once the various regions of the weld can be characterized, the data can help better inform integrated computational materials engineering (ICME) models.

In this study, samples of Ti-17-to-Ti-17 solid-state welds were sectioned via electric-discharge machining (EDM), normal to the weld interface. The cut face was then polished according to metallographic polishing procedures for titanium alloys outlined in [3]. Once polished, the surface was indented with a Buhler microhardness indenter, using $500 \mathrm{~g}$ load force, and a $10 \mathrm{~s}$ dwell time. The first indent was placed at the weld interface and subsequent intents were placed every $100 \mu \mathrm{m}$, extending to $10 \mathrm{~mm}$ from the weld interface, on each side. To ensure accuracy of the values, each sample received multiple, parallel, identical rows of indentations. The Vicker's Microhardness values were recorded and plotted in Figure 1. These microhardness indents could then be used as fiducial markers for recording of EBSD data, enabling precise correlation between microhardness and microstructure. Inverse pole figure maps were used to determine the amount of recrystallization in the beta phase, as well as the degree of dissolution of the alpha phase and whether any re-precipitation occurred.

The microhardness profiles displayed symmetry with respect to the weld interface. The lowest hardness levels occurred at the weld interface, in the DRX zone, and generally increased as distance increased. Both sides of the interface showed local peaks and local minima in hardness at distances of approximately $1100 \mu \mathrm{m}$, and $1600 \mu \mathrm{m}$ from the interface, respectively. The hardness returned to the baseline level, at a distance of approximately $2500 \mu \mathrm{m}$ from the weld interface, which is in agreement with microstructural observations. EBSD data were collected at $\sim 100 \mu \mathrm{m}$ intervals for the first $2 \mathrm{~mm}$, 
and at various locations beyond that distance. The data collected near the weld interface displayed $\beta$ grains smaller significantly smaller than those in the base material, indicating a significant amount of recrystallization, as shown in Figure 2. The EBSD data collected at the interface produced a noisy signal that was attributed to the large amount of deformation present. Data collected $\sim 800 \mu \mathrm{m}$ from the interface revealed the primary $\alpha$-laths had been fully dissolved and then rapidly re-precipitated as multiple laths with different orientations. It also showed evidence of recrystallization of the $\beta$ phase, but not to the same degree as the data collected at the interface. Data collected $\sim 1600 \mu \mathrm{m}$ from the interface showed partially dissolved $\alpha$-laths, with no recrystallization of the $\beta$. The EBSD data, relevant to the points of interest, will be presented and discussed.

\section{References:}

[1] Attallah, M. M., et al., Metallurgical and Materials Transactions A 43 (2012), p. 3149-3161.

[2] G. Lütjering G. and J.C. Williams in "Titanium", (Springer, Berlin).

[3] George F. Vander Voort in "Metallography: Principles and Practice", (McGraw-Hill, New York).

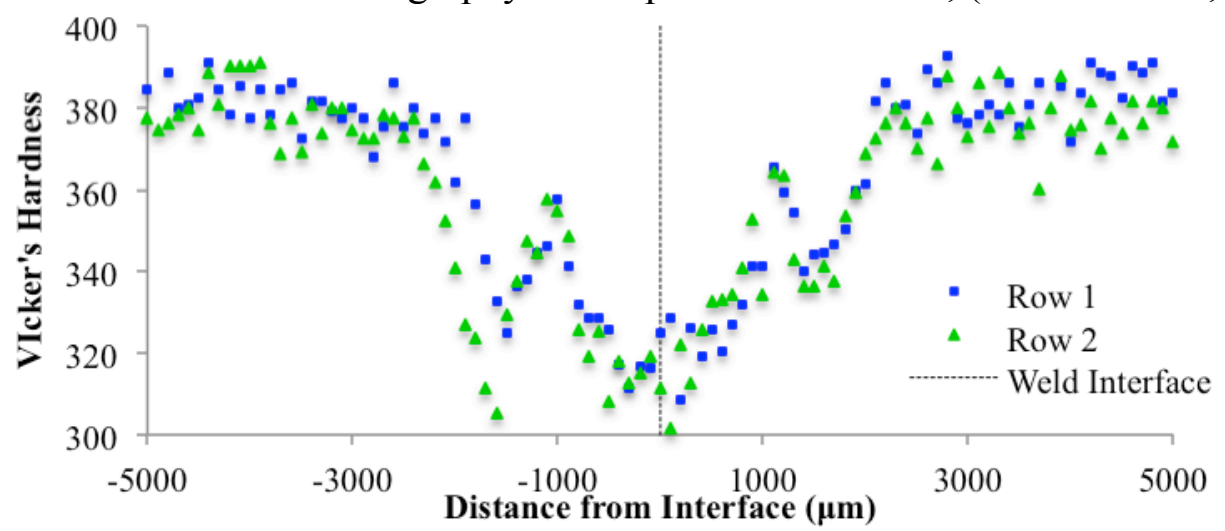

Figure 1. Microhardness profile traversing the weld interface, plotted to $\pm 5000 \mu \mathrm{m}$ from the interface.

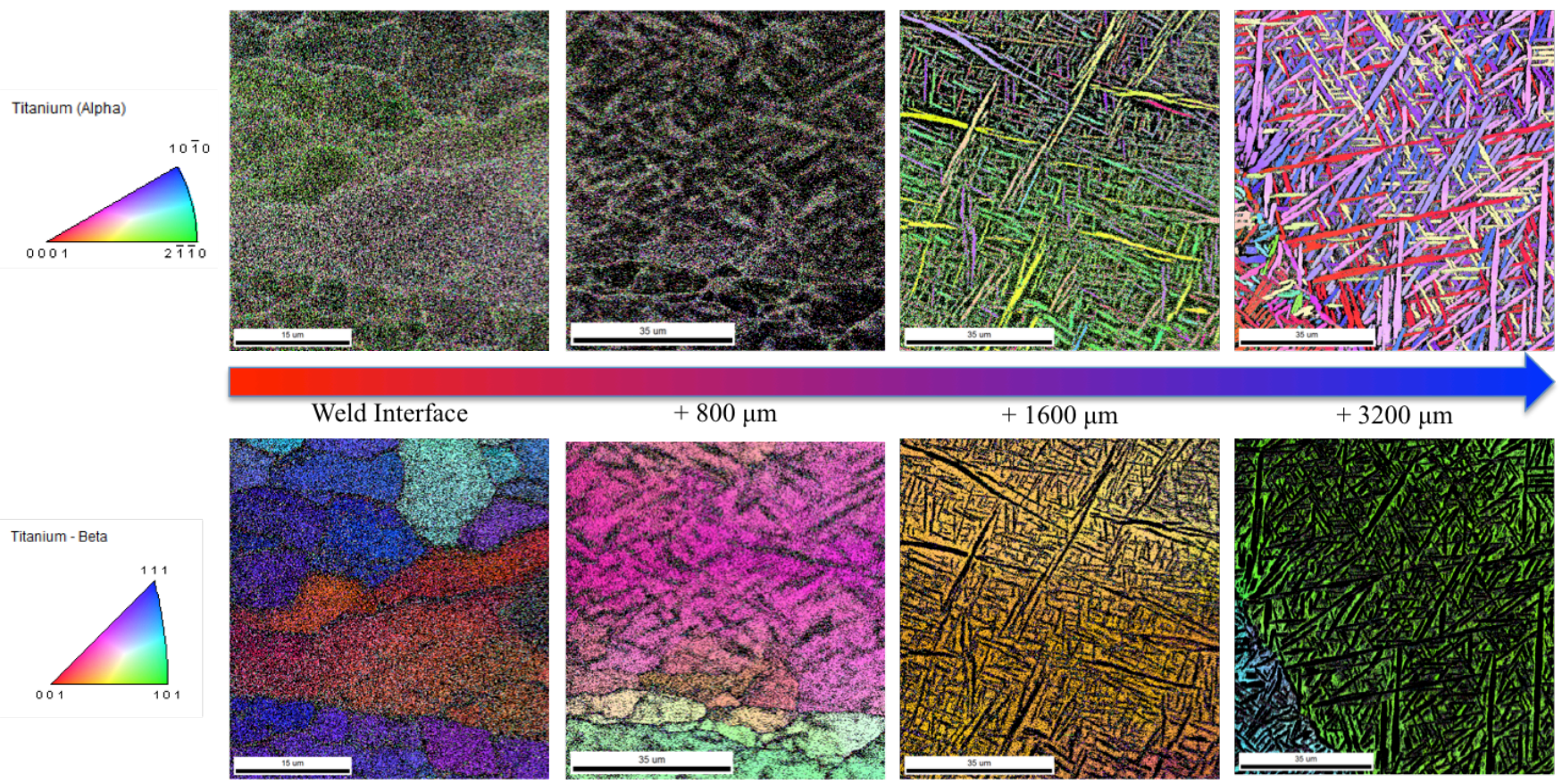

Figure 2. Complimentary alpha and beta phase inverse pole figure maps (top $=\alpha$, bottom $=\beta$ ), collected every $\sim 800 \mu \mathrm{m}$, going from the interface to the base material at $\sim 3200 \mu \mathrm{m}$ away from the interface. 